\title{
Teachers' Learning Activities in the Workplace: How Does Teacher Education Matter?
}

\author{
Joakim Caspersen \\ NIFU-Nordic Institute for Studies in Innovation, Research and Education, Oslo, Norway \\ Email: joakim.caspersen@nifu.no
}

Received 24 November 2014; accepted 5 December 2014; published 14 January 2015

Copyright (C) 2015 by author and Scientific Research Publishing Inc. This work is licensed under the Creative Commons Attribution International License (CC BY). http://creativecommons.org/licenses/by/4.0/

(c) (i) Open Access

\begin{abstract}
The ability of teachers to learn and develop at work is important for the quality of their performance and their well-being. However, research has been ambiguous about what factors can improve it. Two reasons for this ambiguity are discussed in this paper: The links between workplace learning and professional education have often not been included in research studies, and teaching may have special characteristics that make workplace learning difficult. The paper examines new empirical connections between teachers' learning activities at work and the outcome of teacher education, using longitudinal Norwegian survey data. The results show that an active and independent study strategy increases the likelihood of consulting professionals outside work and finding information in books and journals. Furthermore, the introduction of individual characterristics substantially improves the work place impact models, and should be adopted in future research. Finally, it is discussed whether the methodological framework in existing research on teachers' work place learning is consistent with the theoretical point of departure, or whether greater consistency should be sought.
\end{abstract}

\section{Keywords}

Work Place Learning, Teacher Education, Higher Education, Comparative Studies, Study Strategy

\section{Introduction}

Teachers' professional learning and development are essential components of school development, as well as of teachers' professional growth, well-being and success. Muijs et al. (2004: p. 291) argued that teachers' ability to reflect, access new ideas, experiment and share experiences within school cultures gives greater potential for 
school and classroom improvement. Moreover, teachers' learning at work also affects students' attitudes toward learning, teaching processes and achievements. Day et al. (2007) found that teachers in various phases of their professional careers consider continuing professional development activities to be important; these activities represent an investment in their professional lives and are a "means of recharging their batteries" (p. 148). A general feature of the knowledge society is the demand for continual learning and development of professionals, including teachers, after their period of professional preparation is finished (Day \& Sachs, 2004: pp. 3-5). Because teachers benefit from professional preparation and learning, and are demanded to develop and learn, their ability to do so thus becomes an important research topic.

Because the results from research on teachers' workplace learning have been ambiguous, a call for more research has been put forth (Kwakman, 1998, 2001; Taris et al., 2003). In this paper, a specific tradition on research on teachers' learning at work is examined and discussed, a tradition emphasizing the balance among control, demands and support at work. Different models emphasizing these rather simple mechanisms have been put forward, but the results remain unclear. Two potential reasons for this lack of clarity are addressed in this paper. One reason is the omission from the data of initial teacher education in many projects, which might have an influence on later professional learning and development. Professions such as teaching are characterized by a period of professional preparation as an entry to a career. This period of preparation affects the values, motivation and cognitive abilities of participants (Pascarella \& Terenzini, 1991). It also serves as a labor market shelter for the profession and a gateway to the subsequent career (Bills, 2004: pp. 37-60; Collins, 1979; Freidson, 2001: p. 84).

Another reason for inconclusive results might be the research focus solely on teachers. As various researchers (e.g. Barnett, et al., 1987; Hargreaves, D., 2007a; Kennedy, 1990) have pointed out, teaching is a quite distinct profession, with characteristics that have implications for workplace learning. One example could be the privacy and individualism of teaching (e.g. Little, 1990), which may bring about teachers' lack of binding collaboration with colleagues, especially collaboration that supports learning. To shed light on the more specific features of teaching, this paper compares teachers' learning activities with those of physicians. Teaching is sometimes described as a "weak" profession with an unclear knowledge base and low status, whereas medicine is considered the ideal-typical profession, with an established knowledge base, strong academic traditions, strong professional groups and high status (see e.g. Etzioni, 1969; Hargreaves, D., 2007a, 2007b; Myers, 2008). Comparing these two professions should elucidate any shortcomings of the previously used models in research on teachers' workplace learning. According to Haugan's (2011) review of Norwegian research on the general teacher education programme, questions of how teacher education adequately prepares student teachers to become professional teachers have not been addressed in a systematic way, despite a strong focus on this question in international research. The current paper can be seen as an effort to contribute to this in a cumulative way, by linking international research approaches to Norwegian data.

The research question can be stated as follows: What relationships exist among the educational outcomes, workplace characteristics and workplace learning activities of teachers and those of physicians? Learning activities here refer to the actions of professionals who are in need of information or knowledge to handle situations at work. Learning activities can be viewed as attempts to operationalize learning behavior at work, albeit in a general way. Dependent variables measure intentional learning activities. These activities are an important part of an individual's total learning activities, in addition to organized learning activities and informal learning. The aim is to discuss how the inclusion of the contribution from professional education can improve previously used models for workplace learning. This study uses longitudinal data from a Norwegian survey of student teachers and medical students at the end of their professional education and in the early stages of their careers.

\subsection{Previous Research on Teachers' Workplace Learning}

Different perspectives and methodological approaches have been put forward in research on teachers' learning in the workplace. Summarizing and expanding on previous empirical and theoretical studies of early career learning in the workplace in various professions, Eraut (2007) distinguished between learning factors and context factors in a two-triangle model. Learning factors are the challenge and value of the work, feedback and support and confidence and commitment/personal agency. Context factors are allocation and structuring of work, individual participation and expectations of performance and progress and encounters and relationships with people at work. According to Eraut (2007), the important issue in novice professionals' learning is that their 
work has to be sufficiently challenging, yet not so challenging that it reduces their confidence. They must have control of situations so that they can fulfil their learning potential. If they lack control of situations, they may develop negative coping mechanisms, which in turn may prevent learning.

Eraut's (2007) model bears some resemblance to Csikszentmihalyi's (1996) research on how the feeling of flow in performing a task depends on striking a balance between the complexity of the task and the skills of the performer. A similar argument can be found in research using the Job Demand-Control-Support (JDCS) model as a starting point for investigations into teachers' learning in the workplace (Karasek, 1979; Karasek \& Theorell, 1990). This model is based on perceived control over one's work and the demands experienced from the work. When jobs are highly demanding and provide high levels of control, there is potential for learning (active jobs). When demands are high and control is low, stress and poor health result (high-strain jobs). This model was later expanded by the addition of a third dimension that would affect both learning and strain: social support (Karasek \& Theorell, 1990: pp. 68-76). Social interaction is a major component of health and behavioral reactions, and social support in the workplace can affect learning behavior by acting as a buffer between psychological stressors at work and adverse health outcomes.

The results from empirical tests of the learning hypothesis in the JDCS model have been ambiguous (Kwakman, 1998; Parker \& Sprigg, 1999). Taris et al. (2003) tested the hypothesis among Dutch teachers and found that job demands had a negative effect on learning, contrary to the initial assumption. Job control had a positive effect, which was in line with the model. It seemed that the highest levels of learning (and self-efficacy) were found among those with high control and low demands and, furthermore, that the transition from a teaching job with low demands and low control to a job with high demands and low control was particularly harmful. Kwakman (1998) found the hypotheses to be only partially supported; that is, groups of teachers with low or moderate job demands, in combination with high variety in the work performed, experience professional learning situations. Kwakman $(1998,2001)$ called for an expansion of the model and for the inclusion of more variables to predict learning at work for teachers. In their 2010 study, Gijbels et al. concluded that the initial hypothesis put forth by Karasek is intriguing because of its simplicity but that the model needs to be updated with the inclusion of individual learning behavior variables. They included the measure of self-directed learning orientation and found self-directed learning orientation to be a more important predictor of work-related learning than the initial variables in the JDCS model.

Focusing on similar dimensions, McCormack et al. (2006) found that collaboration with colleagues and former peers in an informal, unplanned way is important for novice teachers' professional learning, as is participation in traditional types of formal induction programs and mentoring. These findings are supported by those of Flores (2006), who also emphasized the important role of school leadership. Garet et al. (2001) investigated what makes teachers' professional development effective and found that improvement of professional development activities is more dependent on the duration of the activity (longer lasting activities have more potential for active learning), the collective participation of the teaching staff and the content and coherence of the activity than on the type of professional development activity (workshops or other course-based activities vs. mentoring and induction programs). Klingner (2004) found that teachers' professional development activities are most successful when administrative support is clearly evident, the duration is long and sustained and teachers take ownership of their own professional development activities and mentor their peers. Meirink et al. (2007) found that this type of learning activity leads to changes in teachers' cognition. According to Taris et al., 2003, "the paucity of research addressing learning-oriented outcomes is striking, even more so because many current management practices and philosophies promote the development of self-managing and development-oriented employees” (p. 2). Researchers have also argued that the limited number of tests performed do not adequately take into account how individual factors (such as what the individual brings from higher education and learning behavior) affect workplace learning and continuing professional development (Gijbels et al., 2010; Parker \& Sprigg, 1999).

Again, the research cited here represents a distinct tradition in research on teachers' workplace learning, but has had made a substantial impact. Thus, there are good reasons to follow up on the approaches found in previous research, and develop the research further in a Norwegian context. The variables used in Karasek's JDCS model (Karasek, 1979; Karasek \& Theorell, 1990) are included in the data used in this paper, thus making it possible to draw a direct connection with previous research. Variables measuring perceived control (skill discretion and decision authority), perceived demands (the interaction between control and demands) and perceived support from superiors and colleagues are used as operationalizations of workplace factors affecting workplace learning activities, in line with findings of previous research. 


\subsection{The Importance of Including Individual Learning Characteristics When Analyzing Workplace Learning}

Scholars (e.g. Becker, 1993) have generally assumed that initial professional education is important for performance in subsequent work and for further professional development, but it is rarely discussed why (Baker, 2009). In their comprehensive review of the literature on how college affects students, Pascarella and Terenzini (1991) argued that higher education can have both affective and cognitive outcomes. Cognitive outcomes include not only specific skills, such as problem solving and knowledge of subject matter, but also critical thinking, intellectual flexibility, reflective judgment and cognitive complexity. In the present study, these skills are included in the measures of study strategies in the last year of education. Study strategy includes the critical questioning of the content presented during education, the seeking of knowledge without exams being viewed as the main goal for education and active participation in classes. This way of approaching studies can be viewed as an individual trait, or a personal characteristic. However, it can be argued that, at least partly, it is something that teacher education can encourage and foster. Active student involvement is good for student learning, and involvement is a result of explicit and implicit demands put forward by education (Tinto, 1997). Within the selfregulated learning tradition (e.g. Pintrich, 2004), it is emphasized that students can be active and independent learners who can set goals, monitor their own progress and adjust their own behavior and reflect upon their own practices. Gijbels et al. (2010) found that individual learning orientation is more important for workplace learning behavior than the variables used in previous research on the Karasek model, which was discussed in the subsection titled "Previous Research on Teachers' Workplace Learning".

Study strategies could also be included with reference to affective outcomes. The period of professional education is believed to play an important role in forming or reinforcing the professional identities of students (Kaufman \& Feldman, 2004). One branch of research argues that an important part of professional education is to instill students with a drive for knowledge - that is, an eagerness to continue to learn and develop in their professional careers. Some examples include the analyses of Jensen (2007), Jensen and Lahn (2005) and Smeby (2007) on how different professional communities instill students with a drive for learning. The main concept is that students who are active knowledge seekers and take an active part in their own professional learning and development can be described as "connected" to the relevant professional knowledge base. This, as Smeby (2009) in particular has shown, has consequences for how they approach and seek out learning situations in their professional careers. The implementation of active study strategies during education produces active knowledge seekers at work.

The present study proposes two hypotheses connecting educational outcomes with workplace learning. Hypothesis 1 states that students who find that they have achieved a high educational outcome at the end of their studies will be more active knowledge seekers in their later workplace. Similarly, hypothesis 2 states that students who employ an active and independent study strategy during their education (indicating intellectual flexibility and critical thinking) will be more active knowledge seekers in their later workplace. As previously mentioned, the ambiguous findings of past research on teachers' workplace learning could be a result of omitting the cognitive and affective impact that professional education might have. One aim of the present study is to investigate whether the models used for research on teachers' workplace learning could be further developed by including the contribution from professional education.

\subsection{A Comparison of Teachers and Physicians}

Another reason for ambiguous results in research on teachers' learning in the workplace might be that teaching as a profession has special characteristics compared with other professions. The general models often used might therefore be of limited accuracy ${ }^{1}$. To shed light on this claim, this study compares teachers with physicians.

One argument for comparing teachers and physicians can be found in the different knowledge traditions in the two professions. Teaching is sometimes referred to as a knowledge-weak profession (Hargreaves, D., 2007a). Teaching has poor systems for disseminating new knowledge to the individual teacher (Jensen, 2007), a lack of

${ }^{1}$ On a more technical note, testing the model in only teaching, or in only one professional group at a time, could give conservative estimates because the range in the dependent variables might be restricted when similar work environments are tested (Taris et al., 2003). This can be handled, however, by ensuring sufficient variation within one profession, as Parker and Spriggs (1999) argue. A comparison of different professions also allows variation to be included in the design. 
professional follow-up of teachers in the workplace (Organisation for Economic Co-operation and Development [OECD], 2009) and professional organizations and unions that do not see continuing professional development and learning as important tasks (Karseth \& Nerland, 2007). The term semi-profession, coined by Etzioni (1969), is applied to teaching. By contrast, medicine often serves as an ideal type of profession (Myers, 2008) and is described as having a systematic connection between science and technology and the work of physicians (Freidson, 1970). In teaching, a greater divide has existed between the academic education and research system and the field of professional teaching (Barnett et al., 1987).

When choosing other professional groups for comparison, there are several issues to consider. First of all, one can choose between a "most similar design" and a "most different design” (Przeworski \& Teune, 1970: pp. 3146). Is comparing teaching and medicine a most similar or most different design? Answer depends on whether most attention is given to differences and similarities, but the differences are the most striking. The debate over evidence-based professional practice in medicine and teaching is a good illustration of the differences between these professions, as a push for evidence-based practice has developed in both professions but with different effects. Hargreaves, D. (2007a: pp. 3-17), who has extensively discussed the differences between teaching and medicine, has criticized the scientific field of education for having decoupled teaching from educational research, whereas in medicine, most practitioners often double as researchers with the intent to improve practice and to "translate" and implement research (pp. 4-6). Medicine has been at the forefront of the development of evidence-based procedures, and the development of the field was initially based on the need to link research and practice closer together. The goal was not only to improve practice but also to direct research in a relevant direction for practice. Evidence-based professional practice in education has likewise developed as a response to serious doubts about the quality of educational research and the lack of relevance for educational practice (Biesta, 2007). The knowledge base in teaching has been described as either nonexistent or, if existing, irrelevant to professional needs (Barnett et al., 1987). As a continuation of this, teaching has been described as "not at present a research-based profession” (Hargreaves, D., 2007a: p. 3), whereas medicine has traditionally been considered the prototype of all other professions (Freidson, 1970: p. xvi).

In medicine, evidence-based procedures are established as a part of everyday practice through the development and implementation of procedures and protocols. Many researchers have argued in favor of similar developments in education; however, these developments have been met with opposition and have not been as extensive (see e.g. Biesta, 2007; Hammersley, 2007a; Sackett et al., 1996). The important impact of the development is that teachers do not have the same "toolbox" as do physicians because the tradition of basing professional practice on research results that stem from evidence-based procedures is not as developed in teaching as in medicine.

The use (or lack of use) of scientifically encoded knowledge is reinforced through the organization of the work. Both teachers and physicians have a great deal of what Freidson (1970) referred to as technical autonomy, which is the individual opportunity to decide the technical content of the work. Teachers most often perform their work alone with a group of students and are free to choose their procedures. Physicians also have choice of method but are more guided and restricted by procedures and, it can be claimed, by the consequences of their actions. The act of teaching is an individual enterprise resulting from how school work is organized, whereas doctors' collaborative work may often vary more with the task at hand. As Hargreaves, A. (2000) discussed, teacher collaboration has increased as a response to the traditional, autonomous, one-teacher-one-class model. However, Hargreaves, A. (2000) emphasized that collaboration initiated via imposed curriculum reforms fades away after a short while and that actual teacher collaboration is rare. Great efforts have been made to promote new ways of organizing teachers' work in schools during the past few decades, but many researchers have argued, both internationally (e.g. Jang, 2006) and in Norway (Imsen, 2004), that the actual level of collaboration remains low and that when it does occur, it is often the result of two or more teachers doing together what one teacher could have done alone (Welch, 2000).

Great differences also exist between the two professions in terms of how novice professionals are introduced to their first job. Residency is institutionalized in medical education worldwide, whereas teachers have been described as starting their career with little or no follow-up, in a sink-or-swim manner (Fantilli \& McDougall, 2009).

Comparing teachers and physicians also has its obvious challenges, especially in describing similarities and differences in work context and organization. The images of the two professions presented here might seem a bit caricatured, and they have been met with opposition by scholars (e.g. Hammersley, 2007b). The jobs that teach- 
ers and physicians perform have very different goals: Teachers are responsible for the upbringing and education of children, whereas physicians are responsible for treating the sick. They work in very different environments (schools vs. hospitals, clinics and offices), with very different organization of work and large variations in technical complexity. Grossman et al. (2009: p. 2057) stated that making comparisons across professions is difficult because the differences in status and the nature of the work can be so great. However, these differences can also provide the opportunity to highlight the specific characteristics of a profession, and the similarities should not be understated. Hargreaves, D. (2007b) argued that doctors and teachers are similar in that they make decisions involving complex judgments. They are different in that many doctors draw upon research about the effect of their practice so as to inform and improve their decisions, whereas most teachers do not.

In summary, making a comparison between teaching and medicine can be used to present several hypotheses about the differences between teachers' and physicians' learning activities in the workplace. Hypothesis 3 states that most teachers make less use of scientifically encoded knowledge in the form of finding information in scientific books or journals in their daily professional practice. Furthermore, the lack of a scientifically encoded knowledge base could indicate that teachers seek other knowledge sources, such as colleagues. The tradition of individual teachers and their classes is still a prevailing way of organizing work in schools, although attempts have been made to change this. Thus, the opportunity to gain access to colleagues might be lower for teachers than physicians, which in turn suggests that colleagues are a more frequent source of knowledge for physicians than teachers (hypothesis 4; however, this hypothesis does not say anything about importance). Similarly, making contact with colleagues outside the workplace can be harder for teachers than physicians; hence, teachers will seek them less frequently (hypothesis 5). As a consequence, teachers may reach out to other types of knowledge sources, such as the Internet, to find the information they do not receive from colleagues. The ensuing hypothesis is that teachers find information on the Internet more often than physicians (hypothesis 6).

\section{Data and Methods}

The analyses are based on the combined data from two different panels on two different occasions in a longitudinal survey. The data are part of a larger ongoing Norwegian panel survey called StudData ${ }^{2}$, which is organized and carried out by the Centre for the Study of Professions at Oslo University College. Students from more than 20 different professions from 11 different university colleges and universities are followed during their education and for the first 6 years of their careers.

\subsection{Respondents}

A subsample consisted of two cohorts of teachers and two cohorts of physicians. These cohorts were examined near the end of their studies in the spring of 2001 (cohort 1) and the spring of 2003 (cohort 2) . $^{3}$ Both groups were examined again 3 years later (spring of 2004 and spring of 2006, respectively), after they had moved into schools and hospitals as professionals. A total of 478 teachers and 516 physicians answered the survey 3 years after graduation, and 414 teachers and 357 physicians answered the survey in both phases. The response rates in the year of graduation were $81.6 \%$ for teachers and $75.7 \%$ for physicians. 3 years later, the response rates were $68.3 \%$ for teachers and $63.1 \%$ for physicians.

The surveys were administered in a mandatory class in the year of graduation, whereas postal, electronic and telephone surveys were distributed 3 years after graduation. A panel retention study based on Norwegian public registers indicated that dropout occurred for several reasons: In some instances, individuals left the occupation, but more often, they found other relevant work or were continuing to further their studies (Storøy, 2010).

\subsection{Dependent and Independent Variables}

General questions, as opposed to profession-specific questions, were included in the survey to ensure the comhttp://www.hioa.no/eng/Research/HiOA-research2/Research-at-CSP/prosjekter/StudData (14/01-2012).

${ }^{3}$ There are many routes into teaching in Norwegian schools, but the analyses here included only those teachers with a general teacher education (the largest group of teachers in Norwegian schools). The general teacher education program in Norway comprised eight semesters for this group of students. The final year may consist of different specialities and courses, and some students might have taken this year earlier as part of other educational programs (the analyses indicated that this was true for $5 \%$ of cohort 1 and $13 \%$ of cohort 2 ). To reach everyone before they went their separate ways after graduation, teachers were examined at the end of their 6th semester, and physicians were examined at the end of their 11th or 12th semester before starting residency. 
parability of the groups. The dependent variables are four questions in which the professionals were asked to answer how often (daily, weekly, occasionally or seldom) they seek information from colleagues or superiors in the workplace, from colleagues outside the workplace, from books or other print sources or from the Internet when they need additional knowledge in demanding situations. They are an attempt to operationalize learning activities in the workplace, but they are obviously not a comprehensive operationalization of learning activities. However, all four activities seem important for learning at work and appear to cover the reading and collaborating categories (both with "internal" and "external" colleagues), which have been pointed out as important in previous research (see Kwakman, 2003, for a discussion of teachers' learning activities at work). The variables are also in line with Wenger's (1998: p. 114) distinction between local and global knowledge sources and the claim that knowing in practice involves an interaction between these sources.

The independent variables and items used in the analyses are of two types. One type comprises workplace characteristics, defined as control (measured as skill discretion and decision authority), demands and support (from colleagues and superiors). The other type comprises outcome of education and individual study strategy. Study strategy is an index with 7 items, all with the scale from 1 (disagree) to 7 (agree) (example of items: "I seek out teachers to clarify substantial problems I meet in my studies". "I am present on campus only during classes". Cronbach's alpha, 0.60). The index thus describes the range from an exam-oriented "minimum student" to an extra-effort student who reads additional literature and approaches lecturers for more information. This index was specially designed for the survey and has also been used in other studies (Dæhlen \& Havnes, 2005; Smeby \& Vågan, 2008). The students’ perceived outcome of their education is included as an additive index of 17 items. The students were asked to what extent they feel that their education has provided them with knowledge and skills in different areas on a five-point scale, ranging from 1 (not at all) to 5 (very much so) (examples of items: "My education has provided me with practical skills". "My education has provided me with workspecific knowledge". Cronbach's alpha, 0.88). The measure is a Norwegian adaptation of the National Survey of Student Engagement (NSSE) (see e.g. Zhao \& Kuh, 2004: p. 10), measuring the generic outcomes of education.

The workplace variables were all Norwegian translations of the Karasek model and were taken from the core Job Content Questionnaire (JCQ) and the Quality of Employment Survey (QES) (Karasek et al., 1998). However, 1 item in the measure of skill discretion, 2 items in the measure of social support from supervisors, 2 items on the measure of social support from colleagues and the single item "education required by job" in the measure of skill utilization were not included. The exclusion of these items reduced the number of items from 27 to 21 , and was done to limit the size of the questionnaire. This exclusion should be noted when comparing the results with previous research. The variables measured different aspects of control: skill discretion (example of item: "My work demands a high level of skills". 5 items; Cronbach's alpha, 0.65), and decision authority (example of item: "I can choose how to perform my work". 3 items; Cronbach's alpha, 0.67). Psychological job demands were measured with an index of 5 items (example of item: "My work demands that I work hard". 5 items; Cronbach's alpha, 0.71). Supervisor social support was measured with an index of 2 items (example of item: "My supervisor is helpful getting the work done”. Cronbach’s alpha, 0.88 ), and co-worker social support with 2 items (example of item: "My co-workers are personally interested in me". Cronbach's alpha, 0.68). A factor analysis on both groups ${ }^{4}$ supported a five-factor solution. One item, repetitive work, which in the original model was used (inverted) as a measure of skill discretion, also loaded together with hard work and fast work items in the measure of psychological job demands. When repetitive work was excluded from the factor analyses, Karasek's initial model was reproduced, except that support from colleagues and support from supervisors were combined in one factor and that skill discretion was divided into two factors. However, this is very close to Karasek's initial model, and, thus, the initial structure was kept to ensure comparability with previous research.

The reliability of the independent variables (as measured by Cronbach's alpha) varied from 0.60 to 0.88 . Different limits have been discussed for this kind of reliability measure (see e.g. Henson, 2001). All in all, the reliability measures indicated strong to medium internal consistency. However, the focus of the analyses was to reproduce the general model for workplace learning in previous research, and it was therefore important to use the same models as in previous research. Research investigating the factor structure and the consistency in the JDCS model already exists - but only for the strain hypothesis, not the learning hypothesis. Analysis of factor structure

${ }^{4}$ Principal components analysis with oblimin rotation (as it is assumed that the factors are correlated); minimum factor loading, 0.32 (10\% of factor variance); Kaiser’s criterion used for extraction (eigenvalue > 1). Total explained variance, 60.5\% (see e.g. Kim \& Mueller, 1978, for an overview of criteria and discussion). 
and consistency in the learning hypothesis should be developed more in future research.

Most of the independent variables were formed as statements with a scale from 1 (disagree) to 5 (agree). However, some of the variables were assigned response alternatives from 1 (disagree) to 4 (agree). Because this range is considered too restricted for the items to be used as independent variables (Tabachnick \& Fidell, 2001), all indexes were made additive and were then included in the analyses as standardized variables ( $z$ scores). The respondents' gender and age were included as demographic variables.

The mean scores (or percentages), standard deviation values, observed minimum-maximum scores, scale ranges, number of items and Cronbach's alpha values for the independent variables used are presented in Table 1. Teachers reported more control in terms of skill discretion, had a less independent study strategy during education and were somewhat younger than physicians at graduation (the difference was equal to the 2-year longer medical education program). The results also revealed a higher percentage of female teachers than that of female physicians.

\subsection{Data Analysis}

An examination (involving the calculation of cross tables and chi-square values) of the learning activities that were most frequently used among teachers compared with physicians was carried out to determine the existence of any differences in learning activity characteristics between the two groups. The learning activities were then used as dependent variables, and the workplace characteristics were included as a first step in an ordinal logistic regression. The introduction of study strategies and outcome of education comprised the next step. Regression analysis is used to examine the relationship between a dependent variable and one or more independent variables, with the purpose of predicting the outcome. There are several types of regression analyses, which are appropriate for different types of dependent variables. Because the dependent variables were at an ordinal test level, ordinal logistic analysis (maximum likelihood) was performed to estimate the effect of the independent variables on the probability of performing each of these actions daily, weekly, occasionally or seldom. To ensure that the parallel regression assumption was not violated (i.e. the slope coefficients were identical across each regression, a precondition for using ordinal regression), a Wald test (Brant, 1990) was performed for all models and variables, revealing adequate test statistics (Long, 1997: pp. 140-145; Long \& Freese, 2006: pp. 199-200). Tests were also performed for the product of the linear function (link test), but no indications of curvilinear relationships were found in the models. Potential improvement of the model was examined with a likelihood ratio (LR) test (i.e. whether the $-2 \log$ likelihood significantly improves from one model to another, chi-square distributed). All effects of the independent variables were compared for teachers and physicians with a $t$ test for independent samples.

Table 1. Mean, standard deviation, observed min-max score, scale, number of items and Cronbach's alpha for independent variables.

\begin{tabular}{|c|c|c|c|c|c|c|c|c|}
\hline & \multicolumn{2}{|c|}{ Teachers } & \multicolumn{2}{|c|}{ Physicians } & \multirow[b]{2}{*}{ Obs. min - max } & \multirow[b]{2}{*}{ Scale } & \multirow[b]{2}{*}{ No. of items } & \multirow[b]{2}{*}{ Cronbach’s alpha } \\
\hline & $\mathrm{M}$ & SD & M & SD & & & & \\
\hline Decision authority & 5.9 & 1.4 & 5.8 & 1.5 & $0-9$ & $0-9$ & 3 & 0.65 \\
\hline Skill discretion & 11.1 & 2.0 & $9.7^{*}$ & 2.0 & $1-15$ & $0-15$ & 5 & 0.67 \\
\hline Demands & 8.3 & 2.2 & $7.7^{*}$ & 2.4 & $0-15$ & $0-15$ & 5 & 0.71 \\
\hline Supervisor support & 4.2 & 1.3 & 4.2 & 1.2 & $0-6$ & $0-6$ & 2 & 0.88 \\
\hline Co-worker support & 4.4 & 1.1 & 4.3 & 1.1 & $0-6$ & $0-6$ & 2 & 0.68 \\
\hline Study strategy & 22.0 & 7.0 & $25.5^{*}$ & 7.5 & $1-47$ & $0-48$ & 7 & 0.60 \\
\hline Total outcome of education & 41.3 & 8.4 & $43.3^{*}$ & 9.0 & $0-60$ & $0-76$ & 17 & 0.88 \\
\hline Age at graduation, years & 26.3 & 5.2 & $28.3^{*}$ & 2.7 & $21-55$ & - & - & - \\
\hline \% women & 77 & & $59^{* *}$ & - & - & - & - & - \\
\hline
\end{tabular}

Note: *Significant difference in mean score between teachers and physicians, $p<0.05$ ( $t$ test). ${ }^{* *}$ Significant difference in percentage of women/men, $p<$ 0.05 (chi-square test). 


\subsection{Limitations and Validity}

The data were from a Norwegian context, but most of the literature included was from international research contributions so as to position the research in an international context. The validity of the claims in the paper was nevertheless limited to the Norwegian context, or a similar context. References to Norwegian research were included to show similarities to, and differences from, the international context. Furthermore, the data used sheds light on the learning behaviour of teachers graduated from the previous general teacher education programme, not the current, divided teacher education program. It is possible that data examining students from the new teacher education program would yield different results. This is too early to establish using the same approach as in this paper, as the teacher education program have only recently started, and no students yet have graduated. Future panels of the StudData-survey can address this question.

The independent variables used in the JDCS model are well established. The validity of the independent variables covering study strategy and total outcome of education is less established. Although they are not especially designed for the purpose of this paper, they are indicative of what kind of individual learning variables (in addition to context variables) can be included in analyses of workplace learning.

Study strategy is considered an important outcome of education, but individual study strategy is also affected by academic and social climate. Studying is not only about studying and seeking knowledge but also about socializing (e.g. making friends and having fun). From this perspective, study strategy is only one of the intended outcomes of education. Later periods are about establishing a career, raising a family and finding time for interests that are not work related, but these activities also influence how one acts at work. Thus, a workplace model, no matter how elaborate, does not cover all relevant factors for explaining workplace learning. However, by trying to ground the variables used in previous research and theory, the aim is not to explain everything but rather to test theoretical assumptions in a specific tradition of research on teachers' work place learning. In this way, it is possible to build on previous research and provide a starting point for future analyses in a cumulative manner.

The research design of this project approaches teachers' learning in the workplace as an action that individuals carry out so as to obtain information or knowledge necessary to perform their work. One limitation of this approach is that the operationalization does not explicitly take into account the kinds of situations from which the professionals themselves feel they are learning because this question is not asked. The approach also does not explicitly address questions concerning learning as an identity issue (see e.g. Anderson et al., 1996, for more on the situated learning perspective). In the present study, learning is not exclusively viewed as an individual cognitive phenomenon, which is often implicitly assumed in quantitative research. The approach to learning is not committed to one particular theoretical understanding of learning. The focus is on learning behavior at work as part of a collaborative work culture while acknowledging individual features.

\section{Teachers' and Physicians' Learning Activities}

In Table 2, teachers' and physicians' learning activities are presented as percentages within each activity and profession.

The percentage of physicians (68\%) who reported that they sought advice from superiors or colleagues on a daily basis was more than twice that of teachers (32\%). Although the difference diminished if the "weekly" percentage were included, the teachers still reported that they carried out this type of learning activity more rarely than the physicians ( $80 \%$ vs. $94 \%$, respectively). In terms of consulting professionals outside work, the "daily" percentage was low for both teachers and physicians ( $1 \%$ and $4 \%$, respectively). However, if the "weekly" percentage were included, physicians again were more active (33\%) than teachers (4\%). Teachers were also less active than physicians in finding information in scientific journals and books (13\% vs. $26 \%$ on a daily basis, respectively). There were only small and insignificant differences between teachers and physicians in the use of the Internet. $19 \%$ of the teachers and $13 \%$ of the physicians report to use the internet on a daily basis. Overall, physicians seemed to be significantly more active knowledge seekers than teachers in terms of finding information in print sources, seeking advice from superiors and colleagues at work and consulting professionals outside work.

\section{Workplace Characteristics and the Contribution of Professional Education}

In Table 3, the likelihood of each of the different learning activities is analyzed by means of ordinal logistic regression. Step 1 is a model with only workplace variables; step 2 is a model that introduces variables from the 
Table 2. Learning activities as percentage of responses within each profession.

\begin{tabular}{|c|c|c|c|c|c|c|}
\hline Learning activity & Occasionally & Monthly & Weekly & Daily & Total, \% & $\mathrm{n}$ \\
\hline \multicolumn{7}{|c|}{ Seek advice from superiors or colleagues } \\
\hline Physician & 2 & 4 & 26 & 68 & 100 & 296 \\
\hline Teacher & 7 & 9 & 52 & 32 & 100 & 478 \\
\hline \multicolumn{7}{|c|}{$\chi^{2}=93.56 ; p=0.000$} \\
\hline \multicolumn{7}{|c|}{ Consult professionals outside work } \\
\hline Physician & 42 & 21 & 33 & 4 & 100 & 294 \\
\hline Teacher & 78 & 17 & 4 & 1 & 100 & 469 \\
\hline \multicolumn{7}{|c|}{$\chi^{2}=148.07 ; p=0.000$} \\
\hline \multicolumn{7}{|c|}{ Find information in scientific books or journals } \\
\hline Physician & 5 & 17 & 52 & 26 & 100 & 295 \\
\hline Teacher & 32 & 23 & 32 & 13 & 100 & 475 \\
\hline \multicolumn{7}{|c|}{$\chi^{2}=97.42 ; p=0.000$} \\
\hline \multicolumn{7}{|c|}{ Find information on the Internet } \\
\hline Physician & 27 & 22 & 38 & 13 & 100 & 296 \\
\hline Teacher & 26 & 16 & 38 & 19 & 100 & 475 \\
\hline$\chi^{2}=6.5$ & .086 & & & & & \\
\hline
\end{tabular}

year of graduation. This approach makes it possible to examine any improvement of the analyses from model 1 to model 2, using an LR test (the difference in log likelihood).

The description of the results is done for one dependent variable at the time. The two variables measuring control (decision authority and skill discretion) show no effect on teachers' likelihood of seeking information from superiors or colleagues. Both have an effect for physicians when the study variables are not included, but the effect disappears in model 2. Neither supervisor support nor demands have any effect on the likelihood of teachers or physicians to seek information from superiors or colleagues for teachers. Co-worker support has a positive significant effect for the likelihood of seeking information from superiors or colleagues. For teachers, this effect disappears in model 2. The interaction terms between demands and the two control variables are not significant for either of the groups, and the same holds for gender and age. In terms of study strategy in the year of graduation and total outcome of education, independent and extra-effort medicine students (i.e. students who score high on the study strategy index) have a greater likelihood of seeking information from superiors and colleagues. For both teachers and physicians, the analyses improve significantly from model 1 to model 2, as indicated by the LR test.

In terms of the likelihood of finding information in scientific books or journals, the JDCS variables, the gender variable and the age variable do not have any significant effects. However, in model 2, study strategy has a positive effect for both groups, and perceived total outcome of education has a positive effect for physicians. There is a significant improvement from model 1 to model 2 for both physicians and teachers.

The likelihood of seeking information from professionals outside work increases for teachers who experience high decision authority in their work (i.e. have a high degree of technical autonomy). Physicians who experience a high degree of co-worker support are also more likely to seek information from professionals outside work. The interaction term between decision authority and demands has a significant negative effect for teachers in model 2, contrary to the assumptions in the JDCS model. Study strategy has a significant positive effect on the likelihood of seeking information from professionals outside work for teachers and physicians, and the analyses improve significantly from model 1 to model 2 for both groups.

The likelihood of seeking information on the Internet is increased when physicians have high decision authority; however, the effect disappears in model 2 when the study variables are included. For teachers who experience a high degree of supervisor support, the likelihood of seeking information on the Internet decreases, but this effect disappears in model 2. The older the teachers are at graduation, the less likely they are to seek information on the Internet. Female teachers and physicians also seem less likely to find information on the Internet, 


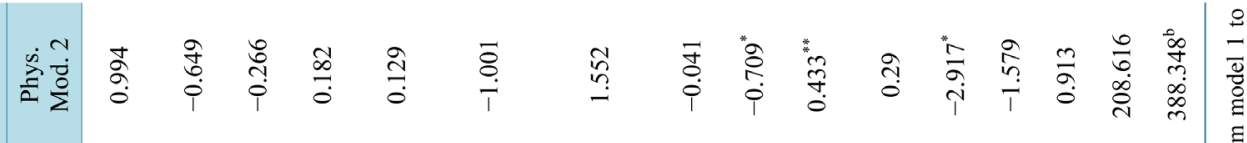

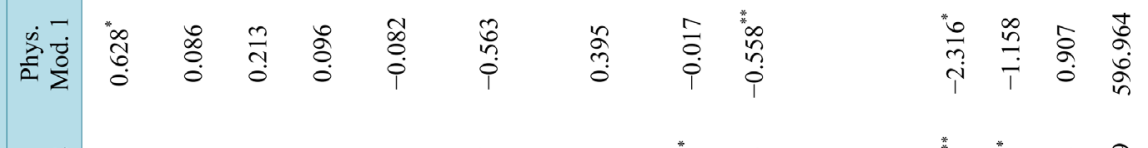

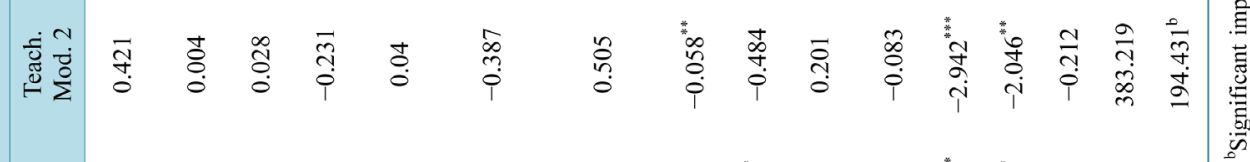

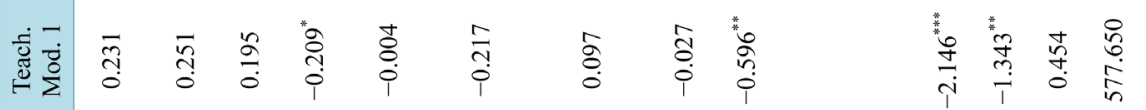

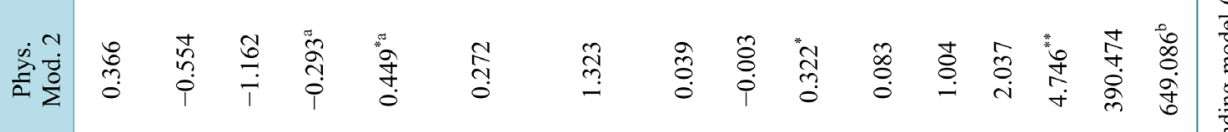

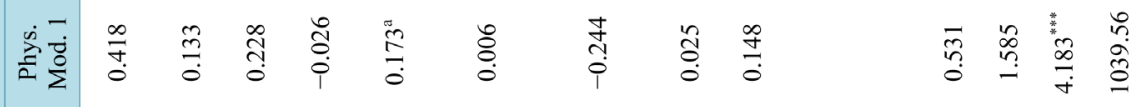

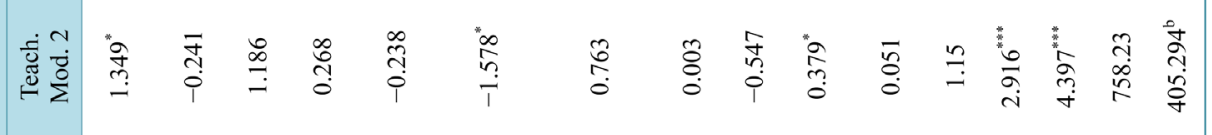

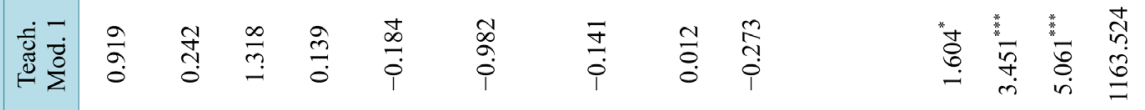

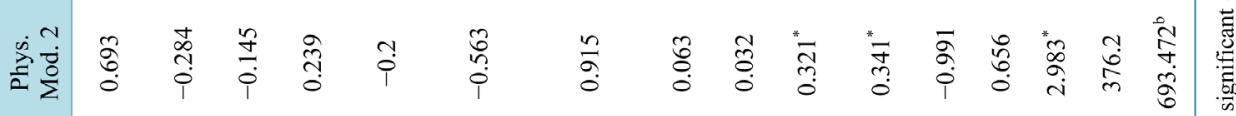

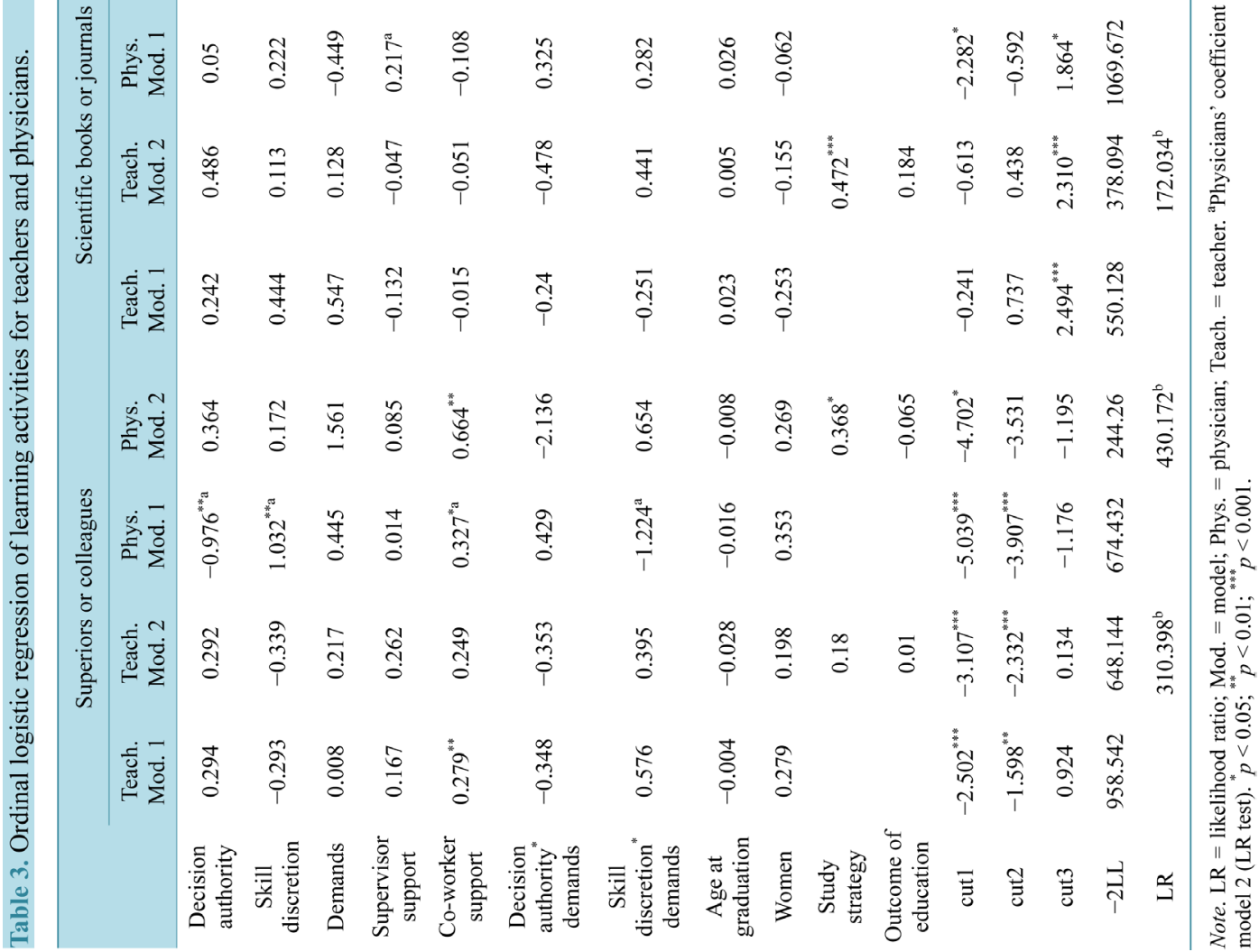


although not in model 2 for teachers. An independent study strategy increases the likelihood of seeking information on the Internet for physicians. The analyses improve significantly from model 1 to model 2 for both groups.

The effects were compared for all independent variables ( $t$ test for independent samples). The variables included in model 1 for teachers were compared with the corresponding variables in model 1 for physicians. The same was done for model 2. Physicians differed from teachers on eight independent variables, only two of which are in model 2. This finding implies that when the study variables are included, there are fewer differences between the variables across the two professions than in the model that includes only workplace variables.

\section{Discussion}

The analyses confirm that the workplace characteristics included in model 1 in the regression analyses provide a limited explanation of teachers' workplace learning. Some of the findings that are in line with the JDCS model are also easily explained: Those who find that they have supportive co-workers have a greater likelihood of using colleagues and superiors as sources for information. When the model is expanded to include study strategy and total outcome of education, the analyses significantly improve. Hypothesis 1 proposes that students who find that they have achieved a high educational outcome at the end of their studies (teacher or medical education) will be more active knowledge seekers at their later workplace. This hypothesis is only partially supported, as a significant effect of total outcome of education is found only among physicians in the likelihood of consulting professionals outside work. Hypothesis 2, which proposes that those students who have an active and independent study strategy during their education will be more active knowledge seekers in their later workplace, is in general supported. An active and independent study strategy increases the likelihood of consulting professionals outside work and finding information in books and journals for both groups, and finding information on the Internet and seeking advice from superiors and colleagues in the physician group. Including the contribution from professional education thus helps to develop and sensitize the models for workplace learning that have been used in previous research. The total outcome of education, however, seems to be less important than the study strategies used during education.

The importance of improving general models of workplace learning by including individual learning variables is discussed further in the following subsection titled "In Need of Improvement: General Models of Workplace Learning". A comparison of teachers and physicians in the present study also shows significant differences in the use of various knowledge sources; in a subsequent subsection titled "The Differences between Teachers and Physicians", it is further substantiated how these differences arise from differences in knowledge traditions and organization of the work. Because the model that is tested and analyzed in this paper has a specific origin, some epistemological issues are discussed in a subsequent subsection titled "Research on Learning at Work".

\subsection{In Need of Improvement: General Models of Workplace Learning}

The specific workplace learning model used in the empirical analyses can be seen as an attempt to operationalize more general and comprehensive models such as Eraut's (1994). At the same time, it replicates the JDCS model, which was developed by Karasek (1979) and Karasek and Theorell (1990) and used in previous research on teachers' workplace learning. The hypothesis that workers with a high degree of control and high workplace demands have a work situation that promotes their learning receives only limited support and, thus, seems to be of limited use across the different work contexts and professions included here. The interaction between decision authority and demands actually has a negative effect on the likelihood of seeking advice from colleagues outside work. This finding is contrary to Karasek's model.

Mikkelsen et al. (2005) referred to a common critique of the JDCS model when they argued that the scales measuring demands do not distinguish between qualitative and quantitative demands and that the model was made for a rather different working life than that faced by teachers and other professionals today. They mentioned, for instance, the introduction of information and communication technology (ICT) as a marked difference between then and now, which would hold true for both teachers and physicians. Furthermore, the differences between the effects of the individual variables might indicate that different mechanisms operate in different professions and, thus, different professional organizations. Thus, the validity of general models for learning and continuing professional development, such as the JDCS model, is ambiguous, or even dubious, and the implication is that studies of workplace learning must be more specific to each profession so as to grasp the important factors promoting professional learning. However, as previously discussed in the subsection titled "Limita- 
tions and Validity”, the individual learning variables (i.e. study strategy and total outcome) are also generic in the analyses. Profession-specific variables should be developed further in future research. Gijbels et al. (2010) referred to common criticisms of the JDCS model when they described it as being inflexible, as focusing on the assumption that the workplace has a determining effect on individual behavior, and as ignoring individual characteristics in both handling stress and learning. Their finding that measures of self-directed learning orientation should be included in the model is supported by the finding of this paper that study strategy during education significantly contributes to workplace learning behavior. Because study strategy is viewed as an educational outcome in the present paper, the importance of elaborating the model goes beyond including individual characteristics. It is also necessary to strive to analyze education and work more in combination. The theoretical discussions of the relationship between education and work, referred to as, for example, theory and practice relations, are plentiful, but the empirical investigations of how these two arenas combine in professional preparation are few and far between.

Initial studies of the JDCS model also featured groups that all involved some type of manual labor with rather specific tasks to perform. In the literature on professions, researchers have often argued that a distinctive feature of a profession is the lack of concrete rules and guidelines for action. The use of discretion with a foundation in professional knowledge is what characterizes the work of both teachers and physicians. Abbott (1988) referred to this as the sequence of diagnosis, inference and treatment. The tasks to be performed are not predefined and must be continually interpreted. In recent years, this opportunity for discretionary decision making has been described by many researchers as being reduced or threatened by the introduction of new control routines and a push for evidence-based practice and standardization in teaching and other professions (see e.g. Aili et al., 2007, for a discussion on this topic). However, a teacher's workday is still varied (i.e. a teacher performs a variety of tasks during a workday), and this lack of predictability in the work situation is quite different from many of the occupations examined by Karasek (Karasek \& Theorell, 1990).

\subsection{The Differences between Teachers and Physicians}

The present study proposes that physicians are more active than teachers in finding information in scientific books or journals in their daily professional practice (hypothesis 3 ) and that colleagues are more important for physicians' workplace learning than for teachers' workplace learning (hypothesis 4). The results of the analyses support both of these hypotheses. In addition, this study proposes that teachers less frequently contact colleagues outside the workplace than do physicians (hypothesis 5). This hypothesis is also supported, thus suggesting that there are specific characteristics of teaching that make workplace learning difficult. This situation was assumed to make teachers more active in using the Internet for finding information (hypothesis 6), but this hypothesis is not supported because the differences between the groups are small in this matter.

All in all, teachers are far less active in seeking knowledge than physicians. One might argue that this behavior is an obvious result of the differences in work situations and work characteristics between the two professions; that is, physicians may have to find information in scientific books and journals to diagnose their patients, whereas teachers do not face this situation, at least not with the same need for precision. However, this argument cannot explain equally well the rather low number of teachers who report that they interact with their colleagues on a daily basis or the low number of teachers, compared with physicians, who consult professionals outside their work. None of the independent variables has any effect on the likelihood of teachers seeking advice from superiors or colleagues. This finding could be interpreted as a result of the "persistence of privacy" in teaching (Little, 1990), a privacy induced by the way school work is organized.

Several causes for teacher individualism have been identified in previous research. Hargreaves, A. (2000: p. 161) summarized some of these causes as follows:

1) The egg-crate school structure divides teachers from one another.

2) The deep-rootedness of teachers' habits and routines makes it easier to build on the existing grammar of schooling, which they have known for decades, than to change to more collaborative forms.

3) When faced with unwanted innovations and accelerated educational reform, teachers have a tendency to minimize and economize effort.

4) Self-doubt about competence makes opening up to colleagues threatening because it would mean exposing one's own flaws and shortcomings.

5) The development of strong emotional bonds with students from whom teachers receive their psychic rewards makes teachers reluctant to share "their" students with other teachers. 
More and more tasks have also been put on teachers' shoulders such as maintaining contact with parents and reporting and documenting work and assessments, thus making it hard for teachers to find the time necessary for building collegial relationships.

In this "emerging age of the collegial professional", emphasis is being placed on the building of "strong professional cultures of collaboration" (Hargreaves, A., 2000: p. 165). Although a great deal has been done to promote teacher collaboration in schools, international research (Hargreaves, A., 1994; Little, 1990; OECD, 2009) and Norwegian research (Vibe et al., 2009) have found that the more binding forms of collaboration are rare among teachers, despite the emphasis placed on them in school reforms. Teaching in teams and coordinating homework between subjects are activities that, respectively, $50 \%$ and $25 \%$ of teachers do weekly, but more binding forms of collaboration (developing teaching material together, observing each other's teaching practices and giving feedback, participating in joint professional development activities) are less common (Vibe et al., 2009: p. 103). The findings of the present study indicate that colleagues represent a more important source for knowledge among physicians than among teachers.

A comparison of teachers and physicians presented in this paper shows that models predicting workplace learning are improved when individual learning variables, such as study strategies, are included. The improvement can be found in medicine, with a strong knowledge tradition, and in teaching, with a weak knowledge tradition. The comparative framework thus indicates that the initial model for workplace learning is weak in both groups, where differences exist not only in the knowledge traditions but also in the organization of the work.

\subsection{Research on Learning at Work}

Another important question is whether the approach to teacher learning used in the present study and in previous research is theoretically coherent. The epistemological or theoretical starting point is relevant when reviewing previous studies on workplace learning, such as Eraut's $(1994,2007)$ work or the JDCS model. Relating back to the two metaphors of learning as acquisition or learning as participation put forth by Sfard (1998), it seems fair to say that the JDCS model emphasizes the acquisition metaphor. Learning is described as "incremental additions to competence" (Karasek \& Theorell, 1990: p. 92) as a result of external factors; learning occurs in situations that are demanding but have a good range of latitude in decision making. Mastering these demanding situations provides motivation for taking on new challenging tasks and seeking new knowledge and learning opportunities. Karasek (Karasek \& Theorell, 1990) would probably not agree with an understanding of learning as participation. However, previous research examining the learning hypothesis in the JDCS model, as well as research on teachers, has given primacy to an operationalization of learning that best fits the metaphor of learning as participation. Thus, a discrepancy seems to exist between Karasek's initial understanding of learning and the understanding of learning in the research examining his learning hypothesis. Incremental additions in competence have not been examined, but social behavior in complex organizations has been the research subject. Future research should continue to discuss how epistemological views correspond to methodological procedures.

Future research on teachers' workplace learning should also endeavor to enhance the models by using better and more profession-specific analytical categories. Greater effort should be put into the operationalization of these categories so as to make them more reflective of a modern working life. Furthermore, approaches and perspectives that allow for individual trajectories across different arenas of professional development with different methodological approaches should be sought. The longitudinal survey approach taken in the present study contributes to mapping and directing the field of future research. However, in-depth studies using different methodologies will surely improve and sharpen the perspectives suggested here.

Fox et al. (2011) showed that beginning teachers' learning experiences may reach beyond the local workplace and include not only personal but also professional networks. In the present study, this way of seeing professional development is addressed only partially, with the inclusion of the question of whether teachers and physicians seek information from professionals outside the workplace and on the Internet. However, because the differences between teachers and physicians are substantial in this regard, researchers should strive to view workplace learning as something more than learning that happens in the workplace and to include learning outside the workplace that is relevant to work.

\section{Conclusion}

The primary finding of this study is that the inclusion of individual learning variables, such as the contribution from professional education, in research on teachers' workplace learning substantially improves the models used 
in research emphasizing the balance among control, demands and support at work. Furthermore, the comparison of teachers with physicians supports the idea that because of the differences among professions, the general models often used are inaccurate and insufficient but are nevertheless substantially improved by including individual learning variables. With regard to research on teachers' workplace learning, a greater effort should be made in future research to include the contribution from professional education and to take into account the idiosyncrasies of teaching as a profession with specific characteristics regarding knowledge and work organization. The scope of future research on workplace learning should be widened by combining methods and approaches of different understandings of workplace learning and by investigating further how teacher education relates to teachers' workplace learning.

\section{References}

Abbott, A. (1988). The System of Professions: An Essay on the Division of Expert Labor. Chicago: University of Chicago Press.

Aili, C., Nilsson, L.-E., Svensson, L. G., \& Denicolo, P. (Eds.) (2007). In Tension between Organization and Profession: Professionals in Nordic Public Service. Lund: Nordic Academic Press.

Anderson, J. R., Reder, L. M., \& Simon, H. A. (1996). Situated Learning and Education. Educational Researcher, 25 , 5-11. http://dx.doi.org/10.3102/0013189X025004005

Baker, D. P. (2009). The Educational Transformation of Work: Towards a New Synthesis. Journal of Education and Work, 22, 163-191. http://dx.doi.org/10.1080/13639080902957822

Barnett, R. A., Becher, R. A., \& Cork, N. M. (1987). Models of Professional Preparation: Pharmacy, Nursing and Teacher Education. Studies in Higher Education, 12, 51-63. http://dx.doi.org/10.1080/03075078712331378270

Becker, G. S. (1993). Human Capital: A Theoretical and Empirical Analysis, with Special Reference to Education (3rd ed.). Chicago: University of Chicago Press. http://dx.doi.org/10.7208/chicago/9780226041223.001.0001

Biesta, G. (2007). Why “What Works” Won't Work: Evidence-Based Practice and the Democratic Deficit in Educational Research. Educational Theory, 57, 1-22. http://dx.doi.org/10.1111/j.1741-5446.2006.00241.x

Bills, D. (2004). The sociology of Education and Work. Malden, MA: Blackwell.

Brant, R. (1990). Assessing Proportionality in the Proportional Odds Model for Ordinal Logistic Regression. Biometrics, 46, 1171-1178. http://dx.doi.org/10.2307/2532457

Collins, R. (1979). The Credential Society: An Historical Sociology of Education and Stratification. New York: Academic Press.

Csikszentmihalyi, M. (1996). Creativity: Flow and the Psychology of Discovery and Invention. New York: HarperCollins.

Day, C., \& Sachs, J. (2004). Professionalism, Performativity and Empowerment: Discourses in the Politics, Policies and Purposes of Continuing Professional Development. In C. Day, \& J. Sachs (Eds.), International Handbook on the Continuing Professional Development of Teachers (pp. 3-32). Maidenhead: Open University Press.

Day, C., Sammons, P., Stobart, G., Kington, A., \& Gu, Q. (2007). Teachers Matter: Connecting Work, Lives and Effectiveness. Maidenhead: Open University Press.

Dæhlen, M., \& Havnes, A. (2005). Studiestrategier i profesjonsutdanningene [Study Strategies in Professional Education]. IngeniørUddannelsernes Pcedagogiske Netværk, 16, 12-13.

Eraut, M. (1994). Developing Professional Knowledge and Competence. London: Falmer Press.

Eraut, M. (2007). Learning from Other People in the Workplace. Oxford Review of Education, 33, 403-422. http://dx.doi.org/10.1080/03054980701425706

Etzioni, A. (1969). The Semi-Professions and Their Organization: Teachers, Nurses, Social Workers. New York: Free Press.

Fantilli, R. D., \& McDougall, D. E. (2009). A Study of Novice Teachers: Challenges and Supports in the First Years. Teaching and Teacher Education, 25, 814-825. http://dx.doi.org/10.1016/j.tate.2009.02.021

Flores, M. A. (2006). Being a Novice Teacher in Two Different Settings: Struggles, Continuities, and Discontinuities. Teachers College Record, 108, 2021-2052.

Fox, A., Wilson, E., \& Deaney, R. (2011). Beginning Teachers’ Workplace Experiences: Perceptions of and Use of Support. Vocations and Learning, 4, 1-24. http://dx.doi.org/10.1007/s12186-010-9046-1

Freidson, E. (1970). Profession of Medicine: A Study of the Sociology of Applied Knowledge. Chicago, IL: University of Chicago Press.

Freidson, E. (2001). Professionalism: The Third Logic. Cambridge: Polity Press.

Garet, M. S., Porter, A. C., Desimone, L., Birman, B. F., \& Yoon, K. S. (2001). What Makes Professional Development Ef- 
fective? Results from a National Sample of Teachers. American Educational Research Journal, 38, 915-945. http://dx.doi.org/10.3102/00028312038004915

Gijbels, D., Raemdonck, I., \& Vervecken, D. (2010). Influencing Work-Related Learning: The Role of Job Characteristics and Self-Directed Learning Orientation in Part-Time Vocational Education. Vocations and Learning, 3, 239-255. http://dx.doi.org/10.1007/s12186-010-9041-6

Grossman, P., Compton, C., Igra, D., Ronfeldt, M., Shahan, E., \& Williamson, P. (2009). Teaching Practice: A Cross-Professional Perspective. Teachers College Record, 111, 2055-2100.

Hammersley, M. (Ed.) (2007a). Educational Research and Evidence-Based Practice. Los Angeles, CA: Sage.

Hammersley, M. (2007b). Educational Research and Teaching: A Response to David Hargreaves’ TTA Lecture. In M. Hammersley (Ed.), Educational Research and Evidence-Based Practice (pp. 18-42). Los Angeles, CA: Sage.

Hargreaves, A. (1994). Changing Teachers, Changing Times: Teachers’ Work and Culture in the Postmodern Age. London: Cassell.

Hargreaves, A. (2000). Four Ages of Professionalism and Professional Learning. Teachers and Teaching: History and Practice, 6, 151-182.

Hargreaves, D. (2007a). Teaching as a Research-Based Profession: Possibilities and Prospects (The Teacher Training Agency Lecture 1996). In M. Hammersley (Ed.), Educational Research and Evidence-Based Practice (pp. 3-17). Milton Keynes: Open University Press.

Hargreaves, D. (2007b). In Defence of Research for Evidence-Based Teaching: A Rejoinder to Martyn Hammersley. In M. Hammersley (Ed.), Educational Research and Evidence-Based Practice (pp. 43-60). Milton Keynes: Open University Press.

Haugan, J. A. (2011). A Systematic Review of Research Regarding Norwegian General Teacher Education 2000-2010. Nordic Studies in Education, 4, 229-244.

Henson, R. K. (2001). Methods, Plainly Speaking. Understanding Internal Consistency Reliability Estimates: A Conceptual Primer on Coefficient Alpha. Measurement and Evaluation in Counseling and Development, 34, 177-189.

Imsen, G. (2004). Skolens Ledelse, skolens kultur og praksis i klasserommet: Er det noen sammenheng? [School Leadership, School Culture and Classroom Practices-What Is the Connection]. In G. Imsen (Ed.), Det ustyrlige klasserommet: Om styring, samarbeid og leringsmiljø i grunnskolen [The Uncontrollable Classroom] (pp.144-164). Oslo: Universitetsforlaget.

Jang, S. J. (2006). Research on the Effects of Team Teaching upon Two Secondary School Teachers. Educational Research, 48, 177-194. http://dx.doi.org/10.1080/00131880600732272

Jensen, K. (2007). The Desire to Learn: An Analysis of Knowledge-Seeking Practices among Professionals. Oxford Review of Education, 33, 489-502. http://dx.doi.org/10.1080/03054980701476055

Jensen, K., \& Lahn, L. (2005). The Binding Role of Knowledge: An Analysis of Nursing Students’ Knowledge Ties. Journal of Education and Work, 18, 305-320. http://dx.doi.org/10.1080/13639080500200542

Karasek, R., Brisson, C., Kawakami, N., Houtman, I., Bongers, P., \& Amick, B. (1998). The Job Content Questionnaire (JCQ): An Instrument for Internationally Comparative Assessments of Psychosocial Job Characteristics. Journal of Occupational Health Psychology, 3, 322-355. http://dx.doi.org/10.1037/1076-8998.3.4.322

Karasek, R., \& Theorell, T. (1990). Healthy Work: Stress, Productivity, and the Reconstruction of Working Life. New York: Basic Books.

Karasek Jr., R. A. (1979). Job Demands, Job Decision Latitude, and Mental Strain: Implications for Job Redesign. Administrative Science Quarterly, 24, 285-308. http://dx.doi.org/10.2307/2392498

Karseth, B., \& Nerland, M. (2007). Building Professionalism in a Knowledge Society: Examining Discourses of Knowledge in Four Professional Associations. Journal of Education and Work, 20, 335-355. http://dx.doi.org/10.1080/13639080701650172

Kaufman, P., \& Feldman, K. A. (2004). Forming Identities in College: A Sociological Approach. Research in Higher Education, 45, 463-496. http://dx.doi.org/10.1023/B:RIHE.0000032325.56126.29

Kennedy, M. M. (1990). Choosing a Goal for Professional Education. In J. Sikula, T. J. Buttery, \& E. Guyton (Eds.), Handbook of Research on Teacher Education (pp. 813-825). New York: Simon \& Schuster Macmillan.

Kim, J. O., \& Mueller, C. W. (1978). Factor Analysis: Statistical Methods and Practical Issues. Beverly Hills, CA: Sage.

Klingner, J. K. (2004). The Science of Professional Development. Journal of Learning Disabilities, 37, $248-255$. http://dx.doi.org/10.1177/00222194040370031001

Kwakman, K. (1998). Professional Learning on the Job of Dutch Secondary Teachers: In Search of Relevant Factors [1]. Journal of In-Service Education, 24, 57-71. http://dx.doi.org/10.1080/13674589800200031

Kwakman, K. (2001). Work Stress and Work-Based Learning in Secondary Education: Testing the Karasek Model. Human 
Resource Development International, 4, 487-501. http://dx.doi.org/10.1080/13678860010004123

Kwakman, K. (2003). Factors Affecting Teachers’ Participation in Professional Learning Activities. Teaching and Teacher Education, 19, 149-170. http://dx.doi.org/10.1016/S0742-051X(02)00101-4

Little, J. W. (1990). The Persistence of Privacy: Autonomy and Initiative in Teachers' Professional Relations. Teachers College Record, 91, 509-536.

Long, J. S. (1997). Regression Models for Categorical and Limited Dependent Variables. Thousand Oaks, CA: Sage.

Long, J. S., \& Freese, J. (2006). Regression Models for Categorical Dependent Variables Using Stata (2nd ed.). College Station, TX: Stata Press.

McCormack, A., Gore, J., \& Thomas, K. (2006). Early Career Teacher Professional Learning. Asia-Pacific Journal of Teacher Education, 34, 95-113. http://dx.doi.org/10.1080/13598660500480282

Meirink, J. A., Meijer, P. C., \& Verloop, N. (2007). A Closer Look at Teachers’ Individual Learning in Collaborative Settings. Teachers and Teaching: Theory and Practice, 13, 145-164. http://dx.doi.org/10.1080/13540600601152496

Mikkelsen, A., Øgaard, T., \& Landsbergis, P. (2005). The Effects of New Dimensions of Psychological Job Demands and Job Control on Active Learning and Occupational Health. Work \& Stress, 19, 153-175. http://dx.doi.org/10.1080/02678370500167808

Muijs, D., Day, C., Harris, A., \& Lindsay, G. (2004). Evaluating CPD: An Overview. In C. Day, \& J. Sachs (Eds.), International Handbook of the Continuing Professional Development of Teachers (pp. 291-310). Maidenhead: Open University Press.

Myers, D. A. (2008). The Teacher as a Service Professional. Action in Teacher Education, 30, 4-11. http://dx.doi.org/10.1080/01626620.2008.10463474

Organisation for Economic Co-Operation and Development (OECD) (2009). Creating Effective Teaching and Learning Environments: First Results from the OECD Teaching and Learning International Survey (TALIS). Paris: OECD.

Parker, S. K., \& Sprigg, C. A. (1999). Minimizing Strain and Maximizing Learning: The Role of Job Demands, Job Control, and Proactive Personality. Journal of Applied Psychology, 84, 925-939. http://dx.doi.org/10.1037/0021-9010.84.6.925

Pascarella, E. T., \& Terenzini, P. T. (1991). How College Affects Students: Findings and Insights from Twenty Years of Research. San Francisco, CA: Jossey-Bass.

Pintrich, P. R. (2004). A Conceptual Framework for Assessing Motivation and Self-Regulated Learning in College Students. Educational Psychology Review, 16, 385-407. http://dx.doi.org/10.1007/s10648-004-0006-x

Przeworski, A., \& Teune, H. (1970). The Logic of Comparative Social Inquiry. New York: Wiley.

Sackett, D. L., Rosenberg, W. M. C., Gray, J. A. M., Haynes, R. B., \& Richardson, W. S. (1996). Evidence Based Medicine: What It Is and What It Isn't. British Journal of Medicine, 312, 71-72. http://dx.doi.org/10.1136/bmj.312.7023.71

Sfard, A. (1998). On Two Metaphors for Learning and the Dangers of Choosing Just One. Educational Researcher, $27,4-13$. http://dx.doi.org/10.3102/0013189X027002004

Smeby, J. C. (2007). Connecting to Professional Knowledge. Studies in Higher Education, 32, 207-224. http://dx.doi.org/10.1080/03075070701267251

Smeby, J. C. (2009). Professional Learning Trajectories. 9th Conference of the European Sociological Association, Lisbon.

Smeby, J. C., \& Vågan, A. (2008). Recontextualising Professional Knowledge-Newly Qualified Nurses and Physicians. Journal of Education and Work, 21, 159-173. http://dx.doi.org/10.1080/13639080802018014

Storøy, S. (2010). Frafallsundersøkelse StudData Panel 2 [Panel Retention Analysis, StudData Panel 2], CSP Working Paper 3 , 2010. Oslo: Centre for the Study of Professions.

Tabachnick, B. G., \& Fidell, L. S. (2001). Using Multivariate Statistics (4th ed.). Boston, MA: Allyn and Bacon.

Taris, T. W., Kompier, M. A. J., De Lange, A. H., Schaufeli, W. B., \& Schreurs, P. J. G. (2003). Learning New Behaviour Patterns: A Longitudinal Test of Karasek's Active Learning Hypothesis among Dutch Teachers. Work and Stress, 17, 1-20. http://dx.doi.org/10.1080/0267837031000108149

Tinto, V. (1997). Classrooms as Communities: Exploring the Educational Character of Student Persistence. Journal of Higher Education, 68, 599-623. http://dx.doi.org/10.2307/2959965

Vibe, N., Aamodt, P. O., \& Carlsten, T. C. (2009). Å være ungdomsskolelærer i Norge-Resultater fra OECDs internasjonale studie av undervisning og lering (TALIS) [Being a Junior High School Teacher in Norway. Results from the OECD Teaching and Learning International Survey]. Oslo: Norwegian Institute for Studies in Innovation, Research and Education (NIFU-STEP).

Welch, M. (2000). Descriptive Analysis of Team Teaching in Two Elementary Classrooms: A Formative Experimental Approach. Remedial and Special Education, 21, 366-376. http://dx.doi.org/10.1177/074193250002100606 
Wenger, E. (1998). Communities of Practice: Learning, Meaning, and Identity. Cambridge: Cambridge University Press. http://dx.doi.org/10.1017/CBO9780511803932

Zhao, C. M., \& Kuh, G. D. (2004). Adding Value: Learning Communities and Student Engagement. Research in Higher Education, 45, 115-138. http://dx.doi.org/10.1023/B:RIHE.0000015692.88534.de 
Scientific Research Publishing (SCIRP) is one of the largest Open Access journal publishers. It is currently publishing more than 200 open access, online, peer-reviewed journals covering a wide range of academic disciplines. SCIRP serves the worldwide academic communities and contributes to the progress and application of science with its publication.

Other selected journals from SCIRP are listed as below. Submit your manuscript to us via either submit@scirp.org or Online Submission Portal.
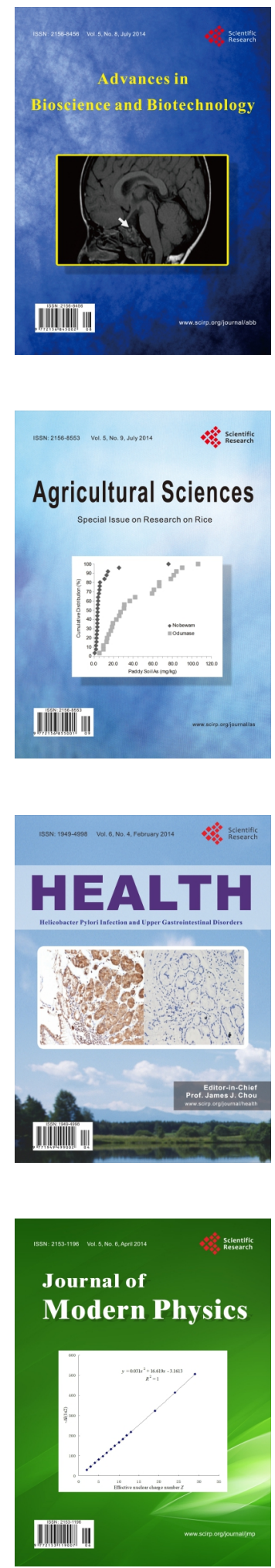
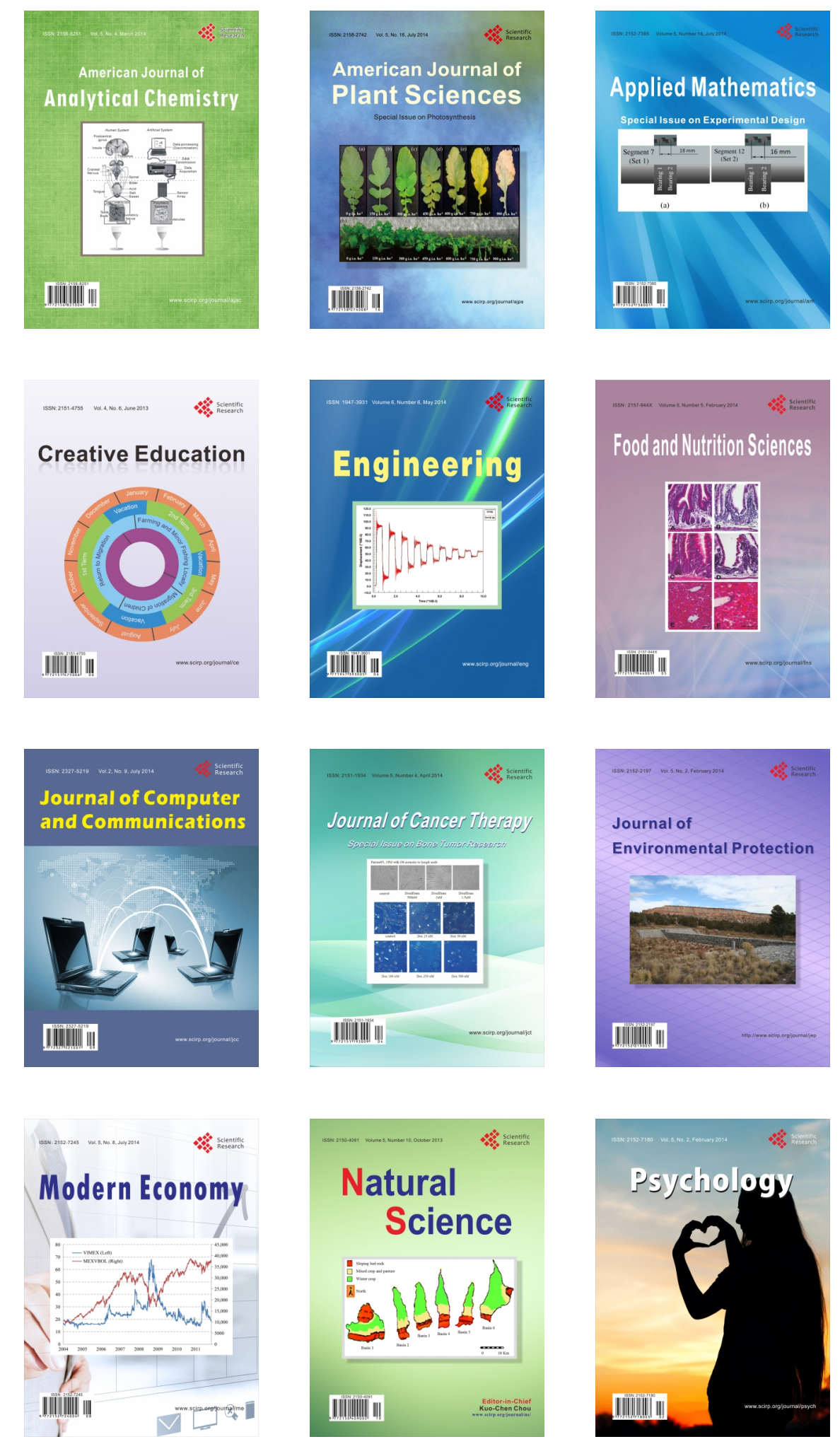